\title{
Anatomical and Morphomertic Study of the Menisci of the Knee Joint in Egyptians
}

\author{
HODA MAHMOUD EL-AASAR, M.D.; MOGEDA M. NASRALLA, M.D.; HEBA AHMED KAMAL, M.D.* and \\ HEND AHMED MOHAMED HUSSEIN, M.Sc.
}

The Departments of Anatomy \& Embryology and Diagnostic Radiology*, Faculty of Medicine, Cairo University

\begin{abstract}
Background: Meniscus injury is common in daily life as well as in sports activities especially football players and runners. Variation of form, thickness and width of the menisci can determine the possibility and type of their injury.

Aim of Study: The aim of this work is to study the different measurements of the different parts of both menisci (distance, circumference, thickness and width) in cadaveric specimens and to correlate these measurements with in vivo MRI measurements, including sex difference of different meniscal parameters.

Materials and Methods: The cadaveric study included fifty menisci of 25 knees of formalin fixed adult human cadavers; Measurements were done with the aid of sliding Vernier caliper and were recorded manually. The MRI study included 76 patients ( 38 male and 38 female), the caliper used for measurements was inbuilt software. The measurements were performed by the same radiologist in all the scans, to prevent inter-observer error.

Results: In the cadaveric study; correlation between the different parameters showed statistically significant positive correlation, while in the MRI study; no significant differences were found in results when comparing male and female subjects, all significant differences were found between medial and lateral menisci, with significant positive correlation between the different parameters.

Conclusion: In cadaveric study, the posterior horn is the thickest and widest part of the meniscus in both medial and lateral menisci. There is also a strong positive correlation between the different parameters of the menisci (distance between anterior and posterior horns, the outer and inner circumference of the menisci). Regarding MRI study, it is concluded that, in agreement with the cadaveric study, the posterior horns of the menisci are the thickest and widest parts. There is also a strong positive correlation in thickness between different parts of the same meniscus, and the width between the different parts of the same meniscus. On the other hand, there were no significant differences in these parameters regarding the sex.
\end{abstract}

Key Words: Anatomy - Menisci - Cadaver-Radiology.

Correspondence to: Dr. Mogeda M. Nasralla, E-Mail: mogedam@yahoo.

\section{Introduction}

THE knee is the largest synovial joint in the body. It consists of femoro-patellar, medial and lateral tibio-femoral articulations. This arrangement offers a fulcrum for propulsion, and allows the limb to bear and transmit the body weight. Because of the wide range of its mobility it has more tendencies for instability, which is countered by intra and extra articular structures [1]. Among these structures are the menisci which are a pair of fibro-cartilaginous semilunar plates (medial and lateral) situated within the knee joint on the tibial condyles deepening its articular surface to receive the femoral condyles [2].

The medial meniscus (MM) has wide posterior horn, narrow anterior horn and more opened Cshaped appearance. The lateral meniscus (LM) has anterior and posterior horns of nearly the same width and has more tight $\mathrm{C}$-shaped appearance. The superior meniscal surface is smooth and concave, producing greater contact with the femoral condyles, while the inferior meniscal surface is flat and rest on the opposing surface of the tibia, The outer border of the meniscus is convex, thick, and attached to the inside of the joint capsule, the inner border is concave, thin and free [1]. The menisci cover $50 \%$ of the medial and $70 \%$ of the lateral surface of tibial plates [3].

Variation in form, thickness and width of the menisci can determine the possibility and kind of injury [4]. In addition, successful meniscus transplantation depends on accurate sizing [5]. Some types of meniscal variants are more liable to degeneration or tear than normal menisci; early detection of these variants can prevent or delay their degeneration or tear by improving habits and life style of the patient [6]. Knowledge of the dimen- 
sions of the normal meniscus may help to differentiate between the normal menisci and pathological ones, as sometimes meniscal variants are misdiagnosed or maldiagnosed as a pathological condition variations. This may be important for planning surgical interventions in the knee joint [7].

The common meniscal variants detected in previous studies are; discoid lateral meniscus, including the Wrisberg variant [8] and discoid medial meniscus [9], anomalous insertion of the medial meniscus [10], hypoplastic menisci [11] and absent menisci [12]

A revolution in the knee diagnosis started with the introduction of magnetic resonance image (MRI). The privilege of MRI is that it is a noninvasive diagnostic tool used in evaluation, diagnosis and monitoring of the menisci. It is found that MRI is superior to computed tomography (CT) in demonstration of intra-articular soft tissue structure of the knee joint [13]. Reports indicated that it is an excellent technique for diagnosis of pathological menisci, evaluation of anatomy of the meniscus size and detection of its normal variants in vivo [14].

\section{Material and Methods}

Material:

\section{Cadaveric study:}

Inclusive criteria: Fifty menisci of 25 knees (14 right and 11 left) of formalin fixed adult human cadavers of unknown age and sex were studied in the Department of Anatomy, Faculty of Medicine, Cairo University through the period from April 2015 to September 2016.

Exclusive criteria: Menisci showing any structural change altering their morphometric analysis such as injuries or advanced degenerative change were excluded.

Radiological study: Serial sections of knee MRI obtained from 76 patients (38 males and 38 females) were collected from Radiology Department Faculty of Medicine Cairo University through the period from April 2015 to September 2016.

\section{Inclusive criteria of MRI cases}

- The age of the individual should be between 18-35 years at the time of imaging.

- Full functionality of the knee joint and full weight bearing.

\section{Exclusive criteria:}

- Any structural changes in menisci which alter its normal measurements and prevent its morphometric analysis such as injury or degenerative changes.

- Any previous surgical intervention in the knee.

Methods:

Cadaveric study:

After removal of the skin and the muscles surrounding the knee joint, the joint cavity was opened by cutting the patellar and collateral ligament horizontally. Menisci were exposed clearly and the tibial condyles with the menisci were then disconnected from the femur by cutting the ACL and PCL near their tibial insertion. Then the menisci were disconnected from the tibial plateau, except at their anterior and posterior horns, by cutting the coronary ligaments.

Morphological parameters: Before cutting the coronary ligaments, the shape of the menisci was studied and accordingly, the meniscus shape was classified as crescentic, C-shape, sickle shape, sided U shaped and sided V shaped. The site of attachment of the meniscal horns was also recorded whether normal or abnormal.

Morphometric parameters: The following measurements were obtained with the aid of sliding Vernier caliper in mms, tabulated and subjected to statistical analysis.

The distance between the anterior horn and the posterior horn of the menisci were measured by placing the Vernier caliper between the apeces of the anterior horn and posterior horn The outer and the inner circumferences of the menisci were measured with non-elastic cotton thread. For this, a piece of thread was placed across the edge of the menisci from the apex of the anterior horn to the apex of posterior horn. This thread was held in place with metallic pins. The length of this thread from the most anterior part of the insertional area to the most posterior part was measured using Vernier caliper. The thickness of the menisci was measured in the middle of each of the three above mentioned parts of the meniscus using the Vernier caliper. The width of the menisci was measured in the middle of each of the three afore mentioned parts using the Vernier caliper.

Radiological study: Serial sections of MRI scans (1.5 Tesla MRI, Philips of Nederland) were taken with the patient lying supine and the knees extended. The images were viewed and the measurements performed using the inbuilt software. 
Images which showed complete view of all parts of medial and lateral menisci were selected for this study. As the caliper used for these measurements was inbuilt software so, there was no discrepancy in the measured values.

The thickness and width of menisci were measured at three regions; the anterior horn, mid- body, and posterior horn. The dimensions were studied in sagittal and coronal planes with T1-weighted, T2-weighted images and Proton Density (PD). Imaging of meniscal structures and contour was better with PD and Gradient fast field echo (FFE) T2-weighted sequences. The thickness and width of the anterior and the posterior horns of each meniscus were measured in sagittal view while the thickness and width of the mid-body were measured in coronal view.

\section{Statistical Methodology:}

All the measurements were tabulated (Tables 1-14) and subjected to statistical analysis using SPSS statistical package version 20 (SPSS Inc., Chicago, IL). Numerical data were expressed as mean and standard deviation. All data was examined by Kolmogorov smirnov test for normality. For quantitative data, the independent $t$-test was used to compare the different parameters regarding side and sex. The paired $t$-test was used within the same meniscus to compare different parameters between the different regions. All tests were two tailed and a $p$-values $<0.05$ and $<0.001$ were considered significant and highly significant, respectively). Bivariate correlation analysis was done to examine the relationship between two numeric data and was graphically summarized by scatterplot diagram. The Pearson correlation indicated: Strength of the relationship (strong or weak) Direction of the relationship:

- Positive (direct): Variables move in the same direction.

- Negative (inverse): Variables move in opposite direction.

\section{Results}

\section{Morphological results:}

In the present study, 50 menisci (25 medial and 25 lateral) were examined. The most common shape for the medial meniscus was the crescentic shape (23 cases, 92\%) (Fig. 1 a) followed by the sickle shape ( 2 cases, $8 \%$ ) (Fig. 1b). Regarding the lateral meniscus, the most common shape was the C-shape (21 cases, 84\%) (Fig. 1c), followed by the sided U shape (4 cases, 16\%) (Fig. 1d).
Other shapes were not encountered neither in medial nor in lateral menisci. Regarding the site of the attachment of the anterior and posterior horns, no abnormalities were detected.

The anterior horn of medial meniscus was attached to the anterior tibial inter-condylar area in front of the anterior cruciate ligament whereas the posterior horn was attached to the posterior tibial inter-condylar area between the attachments of the lateral meniscus and posterior cruciate ligament.

The anterior horn of lateral meniscus was attached in front of the inter-condylar eminence posterolateral to the anterior cruciate ligament whereas the posterior horn was attached behind the inter-condylar eminence in front of the posterior horn of the medial meniscus. The peripheral margins of both menisci were attached to the capsule except in posterolateral aspect of the lateral meniscus where it was grooved by the tendon of popliteus.

Morphometric results:

A- Cadaveric study:

- Distance between anterior and posterior horns of the menisci:

The maximum distance between anterior and posterior horns of medial meniscus was $29 \mathrm{~mm}$ and the minimum was $23 \mathrm{~mm}$ (Table 1, Fig. 2a). While in lateral meniscus, the maximum distance was 14 $\mathrm{mm}$ and the minimum was $9.5 \mathrm{~mm}$ (Table 1, Fig. $2 b)$.

\section{- Outer circumference of the menisci:}

Regarding the outer circumference of the medial meniscus, the maximum measurement was 102 $\mathrm{mm}$ and the minimum was $89 \mathrm{~mm}$ (Table 1, Fig.2c). On the other hand the maximum measurement for lateral meniscus was $100 \mathrm{~mm}$ and the minimum was $80 \mathrm{~mm}$ (Table 1, Fig. 2d).

\section{- Inner circumference of the menisci:}

The maximum inner circumference in medial meniscus was $57 \mathrm{~mm}$ and the minimum was $47 \mathrm{~mm}$ (Table 1, Fig. 2e). While in the lateral meniscus, the maximum measurement was $53 \mathrm{~mm}$ and the minimum was $41 \mathrm{~mm}$ (Table 1, Fig.2f).

\section{- Thickness of anterior 1/3 of the menisci:}

The maximum measurement in medial meniscus was $5 \mathrm{~mm}$ and the minimum was $3.5 \mathrm{~mm}$ (Table 1 , Fig. 3a). In the lateral meniscus, the maximum measurement was $5 \mathrm{~mm}$ and the minimum was $3.5 \mathrm{~mm}$ (Table 1, Fig. 3b). 


\section{- Thickness of middle $1 / 3$ of the menisci:}

Regarding the thickness of middle $1 / 3$ of the medial meniscus, the maximum measurement was $8 \mathrm{~mm}$ and the minimum was $5 \mathrm{~mm}$ (Table 1, Fig. $3 c)$. While the maximum measurement in lateral meniscus was $7 \mathrm{~mm}$ and the minimum was $5 \mathrm{~mm}$ (Table 1, Fig. 3d).

\section{- Thickness of posterior $1 / 3$ of the menisci:}

In measuring thickness of posterior $1 / 3$ of medial meniscus, the maximum measurement was $8 \mathrm{~mm}$ and the minimum was $5 \mathrm{~mm}$ (Table 1, Fig. $3 \mathrm{e})$. Regarding the lateral meniscus, the maximum measurement was $7.5 \mathrm{~mm}$ and the minimum was $5 \mathrm{~mm}$ (Table 1, Fig. 3f).

\section{- Width of anterior $1 / 3$ of the menisci:}

The maximum measurement in medial meniscus was $10 \mathrm{~mm}$ and the minimum was $8 \mathrm{~mm}$ (Table 1 , Fig. 4a). In the lateral meniscus, the maximum measurement was $11.5 \mathrm{~mm}$ and the minimum was 9mm (Table 1, Fig. 4b).

\section{- Width of middle 1/3 of the menisci:}

As for the medial meniscus, the maximum measurement was $12.5 \mathrm{~mm}$ and the minimum was $7 \mathrm{~mm}$ (Table 1, Fig. 4c). In lateral meniscus, the maximum measurement was $13.5 \mathrm{~mm}$ and the minimum was 9mm (Table 1, Fig. 4d).

\section{- Width of posterior 1/3 of the menisci}

The maximum measurement in medial meniscus was $13 \mathrm{~mm}$ and the minimum was $9 \mathrm{~mm}$ (Table 1 , Fig. 4e). The maximum measurement in lateral meniscus was $12 \mathrm{~mm}$ and the minimum was 10.5 $\mathrm{mm}$ (Table 1, Fig. 4f).

\section{B- Radiological Study:}

The following measurements were obtained from MRI of 76 knees.

\section{- Thickness of anterior horn of the menisci:}

The maximum measurement in medial meniscus was $6.6 \mathrm{~mm}$ and the minimum was $4.7 \mathrm{~mm}$ (Table 2, Fig. 5a). While in the lateral meniscus, the maximum measurement was $6.3 \mathrm{~mm}$ and the minimum was $4.2 \mathrm{~mm}$ (Table 2, Fig. 5b).

\section{- Thickness of mid-body of the menisci:}

In all measured MRI cases, the maximum measurement in medial meniscus was $7.9 \mathrm{~mm}$ and the minimum was $5.1 \mathrm{~mm}$ (Table 2, Fig. 5c). On the other hand the maximum measurement in lateral meniscus was $7.2 \mathrm{~mm}$ and the minimum was $5.6 \mathrm{~mm}$ (Table 2, Fig. 5c).

\section{- Thickness of posterior horn of the menisci:}

Regarding the thickness of the posterior horn of the medial meniscus, the maximum measurement was $8.9 \mathrm{~mm}$ and the minimum was $5 \mathrm{~mm}$ (Table 2 , Fig. 5a). While in lateral meniscus, the maximum measurement in was $8.6 \mathrm{~mm}$ and the minimum was $5.9 \mathrm{~mm}$ (Table 2, Fig. 5b).

\section{- Width of anterior horn of the menisci:}

The maximum measurement in medial meniscus was $9.8 \mathrm{~mm}$ and the minimum was $8 \mathrm{~mm}$ (Table 2, Fig. 5d). Regarding the lateral meniscus, the maximum measurement in was $12.2 \mathrm{~mm}$ and the minimum was 9mm (Table 2, Fig. 5e).

\section{- Width of mid-body of the menisci}

As for the medial meniscus, the maximum measurement was $11.4 \mathrm{~mm}$ and the minimum was $6.9 \mathrm{~mm}$. (Table 2, Fig. 5f). In lateral meniscus, the maximum measurement in was $13.1 \mathrm{~mm}$ and the minimum was $9.2 \mathrm{~mm}$. (Table 2, Fig. 5f).

\section{- Width of posterior horn of the menisci:}

In measuring width of posterior horn of medial meniscus, the maximum measurement was $14.9 \mathrm{~mm}$ and the minimum was $12.6 \mathrm{~mm}$. (Table 2, Fig. $5 \mathrm{~d}$ ). The maximum measurement in lateral meniscus was $12.2 \mathrm{~mm}$ and the minimum was $9.2 \mathrm{~mm}$ (Table 2, Fig. 5f).

Statistical results:

A- Cadaveric study:

- In the present study, the values of the measurements of the distance between anterior and posterior horn in the medial meniscus, in all cases, showed higher values compared with those of the lateral meniscus which was statistically highly significant $(p$-value $=0.000)($ Table 1$)$.

- The values of the measurements of the outer circumference of the medial meniscus, in all cases, showed higher values than those of the lateral one and it was statistically highly significant ( $p$-value $=0.000)($ Table 1$)$.

- The values of the measurements of the inner circumference of the medial meniscus, in all cases, showed higher values compared with those of that of the lateral meniscus and this difference was statistically highly significant $(p$-value $=0.000)$ (Table 1).

- Comparing thickness of different parts between medial and lateral menisci in the present study, the measurements of the thickness of the middle $1 / 3$ of the medial meniscus showed higher values than with those of the lateral meniscus 
which was statistically highly significant $(p$-value $=$ 0.000 ). The values of thickness of the anterior and posterior $1 / 3$ of medial meniscus were also higher than the lateral, but these differences were statistically non-significant (Table 1).

- Comparing the thickness of the different parts of the meniscus on the same side, it was found that the posterior horn is the thickest part of the meniscus followed by the mid-body then the anterior horn and it was statistically highly significant in both lateral and medial menisci $(p$-value $=0.000)$ (Table 2).

- Comparing the width of different parts between both menisci in the present study, the measurements of the width of anterior $1 / 3$ of lateral meniscus showed higher values compared with those of the medial meniscus and it was statistically highly significant $(p$-value $=0.000)$, and the measurements of the width of middle $1 / 3$ of the lateral meniscus were larger than that of medial meniscus and this difference was statistically significant $(p$ value $=0.03$ ). On the other hand, the measurements values of the width of posterior $1 / 3$ of the medial meniscus were higher than the lateral, but it was statistically non-significant (Table 1).

- Comparing the width of different parts of the meniscus on the same side, it was found that the posterior horn was the widest part of the meniscus followed by the mid-body then the anterior horn and it was statistically highly significant in both lateral and medial menisci $(p$-value $=0.000)($ Table $3)$.

\section{Correlation between different parameters:}

- The correlation between the measurements of each of the outer circumference, inner circumference and the distance between the anterior and posterior horn of the medial meniscus showed statistically highly significant positive correlation $(p$-value $=0.000)($ Figs. 6a,b\&c).

- The correlation between the measurements of each of the outer circumference, inner circumference and the distance between the anterior and posterior horn of the lateral meniscus showed statistically highly significant positive correlation $(p$-value $=0.000)($ Figs. 6d,e\&f).

B- Radiological study:

a- Thickness of the different parts of the menisci:

- The measurements of thickness of the anterior horn, mid-body and posterior horn in males were slightly higher than those of females both in medial and lateral menisci, but these differences were statistically non-significant (Table 4, Figs. 7a,b).
- In comparing thickness of different regions between medial and lateral menisci in the present study, regardless sex, it was found that the measurements of the thickness of the anterior horn of the medial meniscus showed higher values compared with those of the lateral meniscus which was statistically highly significant ( $p$-value $=0.001$ ). While the measurements of the thickness of the mid-body of the lateral meniscus showed higher values than those of the medial meniscus and it was statistically significant ( $p$-value $=0.03$ ), but there was no statistically significant difference in the measurements of thickness of the posterior horn between both menisci $(p$-value $=0.4)$ (Table 5, Fig. 7c).

- In comparing the thickness of different parts of the meniscus on the same side, it was found that the posterior horn was the thickest part of the meniscus followed by the mid-body then the anterior horn and it was highly statistically significant in both medial and lateral menisci $(p$-value $=0.000)$ (Figs. 7a,b).

\section{$\mathrm{b}$ - Width of the different parts of the menisci:}

- The measurements of width of the anterior horn, mid-body and posterior horn in males were slightly higher than those of females both in medial and lateral menisci, but these differences were statistically non-significant (Table 4).

- Comparing the width of different regions between medial and lateral menisci, regardless sex, it was found that the measurements of the anterior horn and the mid-body of the lateral meniscus showed higher values compared with those of the medial meniscus and it was statistically highly significant ( $p$-value $=0.000$ ). While the measurements of the width of the posterior horn medial meniscus showed higher values than those of the lateral meniscus which was statistically highly significant $(p$-value $=0.000)($ Table 5, Fig. 7f $)$.

- Comparing the width of the different parts of the meniscus in the same side, it was found that the posterior horn is the widest part of the meniscus followed by the mid-body then the anterior horn and it was statistically highly significant in both medial and lateral menisci $(p$-value $=0.000)$. (Figs . $7 \mathrm{~d}, \mathrm{e})$.

\section{Correlation between different parameters:}

The correlation between the measurements of the thickness between the different regions of the medial meniscus showed statistically highly significant positive correlation ( $p$-value $=0.000)$ (Figs. $8 \mathrm{a}, \mathrm{b} \& \mathrm{c}$ ). The present study also showed a statisti- 
cally highly significant positive correlation between the measurements of the thickness between the different regions of the lateral meniscus $(p$-value $=$ 0.000) (Figs. 8d,e\&f). Correlation between the measurements of the width between the different regions of the medial meniscus showed statistically highly significant positive correlation $(p$-value $=$ 0.000) (Figs. 9a,b\&c). Correlation between the measurements of the width between the different regions of the lateral meniscus showed statistically highly significant positive correlation $(p$-value $=$ 0.000) (Figs. 9d,e\&f).

Table (1): The minimum, maximum and mean $( \pm S D)$ values of different parameters of medial and lateral menisci in (mm) (cadaveric study).

\begin{tabular}{|c|c|c|c|c|c|c|}
\hline Parameters & Meniscus side & $\mathrm{N}$ & Minimum & Maximum & Mean \pm SD & $p$-value \\
\hline \multirow{2}{*}{$\begin{array}{l}\text { Distance between anterior } \\
\text { and posterior horn }\end{array}$} & Medial & 25 & 23 & 29 & $25.80 \pm 2.18$ & \multirow[t]{2}{*}{$.000^{*}$} \\
\hline & Lateral & 25 & 9.5 & 14 & $11.36 \pm 1.58$ & \\
\hline \multirow[t]{2}{*}{ Outer circumference length } & Medial & 25 & 89 & 102 & $95.16 \pm 3.62$ & \multirow[t]{2}{*}{$.000^{*}$} \\
\hline & Lateral & 25 & 80 & 100 & $88.20 \pm 4.95$ & \\
\hline \multirow[t]{2}{*}{ Inner circumference length } & Medial & 25 & 47 & 57 & $51.32 \pm 3.29$ & \multirow[t]{2}{*}{$.000 *$} \\
\hline & Lateral & 25 & 41 & 53 & $45.28 \pm 3.16$ & \\
\hline \multirow[t]{2}{*}{ Thickness anterior $1 / 3$} & Medial & 25 & 3.5 & 5 & $4.34 \pm 0.47$ & \multirow[t]{2}{*}{.174} \\
\hline & Lateral & 25 & 3.5 & 5 & $4.16 \pm 0.45$ & \\
\hline \multirow[t]{2}{*}{ Thickness middle $1 / 3$} & Medial & 25 & 5 & 8 & $6.22 \pm 0.95$ & \multirow[t]{2}{*}{$.04 *$} \\
\hline & Lateral & 25 & 5 & 7 & $5.74 \pm 0.71$ & \\
\hline \multirow[t]{2}{*}{ Thickness posterior $1 / 3$} & Medial & 25 & 5 & 8 & $6.78 \pm 0.97$ & \multirow[t]{2}{*}{.537} \\
\hline & Lateral & 25 & 5 & 7.5 & $6.62 \pm 0.85$ & \\
\hline \multirow[t]{2}{*}{ Width anterior $1 / 3$} & Medial & 25 & 8 & 10 & $8.92 \pm 0.67$ & \multirow[t]{2}{*}{$.000^{*}$} \\
\hline & Lateral & 25 & 9 & 11.5 & $10.00 \pm 0.80$ & \\
\hline \multirow[t]{2}{*}{ Width middle $1 / 3$} & Medial & 25 & 7 & 12.5 & $10.24 \pm 1.59$ & \multirow[t]{2}{*}{$.03^{*}$} \\
\hline & Lateral & 25 & 9 & 13.5 & $11.14 \pm 1.32$ & \\
\hline \multirow[t]{2}{*}{ Width posterior $1 / 3$} & Medial & 25 & 9 & 13 & $11.20 \pm 1.27$ & \multirow[t]{2}{*}{.895} \\
\hline & Lateral & 25 & 10.5 & 12 & $11.16 \pm 0.81$ & \\
\hline
\end{tabular}

*Statistically significant: $p$-value $<0.05$, highly significant $\leq 0.001$ using independent $t$-test.

Table (2): Comparisons of the thickness between the different parts of the meniscus of the same side in $(\mathrm{mm})$ (cadaveric study).

\begin{tabular}{|c|c|c|}
\hline Meniscus & Mean \pm SD & $p$-value \\
\hline \multicolumn{3}{|l|}{ Medial meniscus: } \\
\hline \multicolumn{3}{|l|}{ Pair 1: } \\
\hline Thickness anterior $1 / 3$ & $4.34 \pm 0.47$ & $.000^{*}$ \\
\hline Thickness middle $1 / 3$ & $6.22 \pm 0.95$ & \\
\hline \multicolumn{3}{|l|}{ Pair 2: } \\
\hline Thickness anterior $1 / 3$ & $4.34 \pm 0.47$ & $.000^{*}$ \\
\hline Thickness posterior $1 / 3$ & $6.78 \pm 0.97$ & \\
\hline \multicolumn{3}{|l|}{ Pair 3} \\
\hline Thickness posterior $1 / 3$ & $6.78 \pm 0.97$ & $.000^{*}$ \\
\hline Thickness middle $1 / 3$ & $6.22 \pm 0.95$ & \\
\hline \multicolumn{3}{|l|}{ Lateral meniscus: } \\
\hline \multicolumn{3}{|l|}{ Pair 1: } \\
\hline Thickness anterior $1 / 3$ & $4.16 \pm 0.45$ & $.000^{*}$ \\
\hline Thickness middle $1 / 3$ & $5.74 \pm 0.71$ & \\
\hline \multicolumn{3}{|l|}{ Pair 2: } \\
\hline Thickness anterior $1 / 3$ & $4.16 \pm 0.45$ & $.000^{*}$ \\
\hline Thickness posterior $1 / 3$ & $6.62 \pm 0.85$ & \\
\hline \multicolumn{3}{|l|}{ Pair 3: } \\
\hline Thickness posterior $1 / 3$ & $6.62 \pm 0.85$ & $.000^{*}$ \\
\hline Thickness middle $1 / 3$ & $5.74 \pm 0.71$ & \\
\hline
\end{tabular}

* Statistically highly significant using paired $t$-test
Table (3): Comparisons of the width between the different parts of the meniscus of the same side in $(\mathrm{mm})$ (cadaveric study).

\begin{tabular}{|c|c|c|}
\hline Meniscus & Mean \pm SD & $p$-value \\
\hline \multicolumn{3}{|l|}{ Medial meniscus: } \\
\hline \multicolumn{3}{|l|}{ Pair 1: } \\
\hline Width anterior $1 / 3$ & $8.92 \pm 0.67$ & $.000^{*}$ \\
\hline Width middle $1 / 3$ & $10.24 \pm 1.59$ & \\
\hline \multicolumn{3}{|l|}{ Pair 2: } \\
\hline Width anterior $1 / 3$ & $8.92 \pm 0.67$ & $.000 *$ \\
\hline Width posterior $1 / 3$ & $11.20 \pm 1.27$ & \\
\hline \multicolumn{3}{|l|}{ Pair 3: } \\
\hline Width middle $1 / 3$ & $10.24 \pm 1.59$ & $.000^{*}$ \\
\hline Width posterior $1 / 3$ & $11.20 \pm 1.27$ & \\
\hline \multicolumn{3}{|l|}{ Lateral meniscus: } \\
\hline \multicolumn{3}{|l|}{ Pair 1: } \\
\hline Width anterior $1 / 3$ & $10.00 \pm 0.80$ & $.000 *$ \\
\hline Width middle $1 / 3$ & $11.14 \pm 1.32$ & \\
\hline \multicolumn{3}{|l|}{ Pair 2: } \\
\hline Width anterior $1 / 3$ & $10.00 \pm 0.80$ & $.000 *$ \\
\hline Width posterior $1 / 3$ & $11.16 \pm 0.81$ & \\
\hline \multicolumn{3}{|l|}{ Pair 3: } \\
\hline Width middle $1 / 3$ & $11.14 \pm 1.32$ & $.000 *$ \\
\hline Width posterior $1 / 3$ & $11.16 \pm 0.81$ & \\
\hline
\end{tabular}

* Statistically highly significant using paired $t$-test 
Table (4): The minimum, maximum and mean $( \pm$ SD) values of thickness at different parts of medial and lateral menisci on basis of sex in ( $\mathrm{mm}$ ) (radiological study).

\begin{tabular}{lllcccc}
\hline Meniscus & Sex & $\mathrm{N}$ & Minimum value & Maximum value & Mean \pm SD & $p$-value \\
\hline Thickness of anterior horn & Male & 38 & 4.70 & 6.60 & $5.64 \pm 0.66$ & .398 \\
Medial meniscus & Female & 38 & 4.70 & 6.60 & $5.51 \pm 0.64$ & \\
Thickness of mid-body & Male & 38 & 5.00 & 7.90 & $6.27 \pm 0.84$ & .816 \\
Medial meniscus & Female & 38 & 5.10 & 7.80 & $6.23 \pm 0.83$ & \\
Thickness of posterior horn & Male & 38 & 5.00 & 8.90 & $7.03 \pm 0.89$ & .826 \\
Medial meniscus & Female & 38 & 5.90 & 8.50 & $6.98 \pm 0.76$ & \\
Thickness of anterior horn & Male & 38 & 4.20 & 6.30 & $5.29 \pm 0.70$ & .376 \\
Lateral meniscus & Female & 38 & 4.30 & 6.30 & $5.16 \pm 0.67$ & \\
Thickness of mid- body & Male & 38 & 5.60 & 7.20 & $6.55 \pm 0.51$ & .317 \\
lateral meniscus & Female & 38 & 5.60 & 7.20 & $6.43 \pm 0.54$ & \\
Thickness of posterior horn & Male & 38 & 5.90 & 8.60 & $6.97 \pm 0.76$ & .518 \\
Lateral meniscus & Female & 38 & 6.00 & & & \\
\multicolumn{2}{l}{ Non-significant using independent $t$-test } & & & & &
\end{tabular}

Table (5): The minimum, maximum and mean $( \pm S D)$ values of thickness and width of medial and lateral menisci at their different three parts regardless sex in $(\mathrm{mm})$ (radiological study).

\begin{tabular}{|c|c|c|c|c|c|c|}
\hline Parameters & Meniscus side & $\mathrm{N}$ & Minimum & Maximum & Mean \pm SD & $p$-value \\
\hline Thickness of anterior horn & $\begin{array}{l}\text { Medial } \\
\text { Lateral }\end{array}$ & $\begin{array}{l}76 \\
76\end{array}$ & $\begin{array}{l}4.7 \\
4.2\end{array}$ & $\begin{array}{l}6.6 \\
6.3\end{array}$ & $\begin{array}{l}5.57 \pm 0.65 \\
5.23 \pm 0.68\end{array}$ & $.001 *$ \\
\hline Thickness of mid body & $\begin{array}{l}\text { Medial } \\
\text { Lateral }\end{array}$ & $\begin{array}{l}76 \\
76\end{array}$ & $\begin{array}{l}5.1 \\
5.6\end{array}$ & $\begin{array}{l}7.9 \\
7.2\end{array}$ & $\begin{array}{l}6.25 \pm 0.83 \\
6.49 \pm 0.52\end{array}$ & $.03 *$ \\
\hline Thickness of posterior horn & $\begin{array}{l}\text { Medial } \\
\text { Lateral }\end{array}$ & $\begin{array}{l}76 \\
76\end{array}$ & $\begin{array}{l}5 \\
5.9\end{array}$ & $\begin{array}{l}8.9 \\
8.6\end{array}$ & $\begin{array}{l}7.01 \pm 0.82 \\
6.92 \pm 0.74\end{array}$ & .4 \\
\hline Width of anterior horn & $\begin{array}{l}\text { Medial } \\
\text { Lateral }\end{array}$ & $\begin{array}{l}76 \\
76\end{array}$ & $\begin{array}{l}8 \\
9\end{array}$ & $\begin{array}{l}9.8 \\
12.2\end{array}$ & $\begin{array}{l}9.26 \pm 0.50 \\
10.16 \pm 0.64\end{array}$ & $.000^{*}$ \\
\hline Width of mid body & $\begin{array}{l}\text { Medial } \\
\text { Lateral }\end{array}$ & $\begin{array}{l}76 \\
76\end{array}$ & $\begin{array}{l}6.9 \\
9.2\end{array}$ & $\begin{array}{l}11.4 \\
13.1\end{array}$ & $\begin{array}{l}10.23 \pm 0.89 \\
11.21 \pm 0.67\end{array}$ & $.000 *$ \\
\hline Width of posterior horn & $\begin{array}{l}\text { Medial } \\
\text { Lateral }\end{array}$ & $\begin{array}{l}76 \\
76\end{array}$ & $\begin{array}{l}12.6 \\
9.2\end{array}$ & $\begin{array}{l}14.9 \\
12.2\end{array}$ & $\begin{array}{l}13.54 \pm 0.74 \\
11.40 \pm 0.61\end{array}$ & $.000 *$ \\
\hline
\end{tabular}

*Statistically significant a: $p$-value $<0.05$, highly significant $\leq 0.001$ using independent $t$-test.

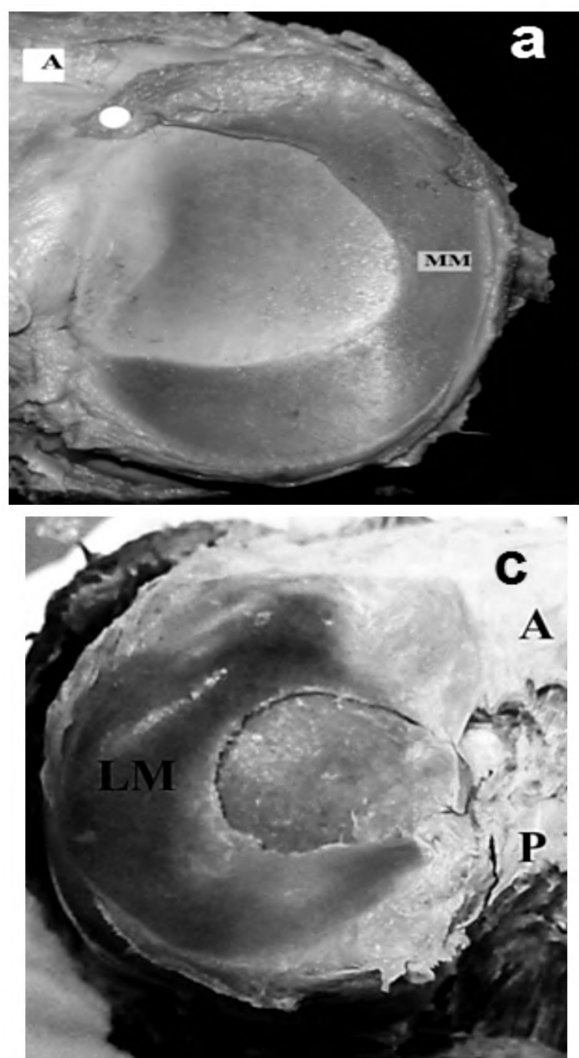

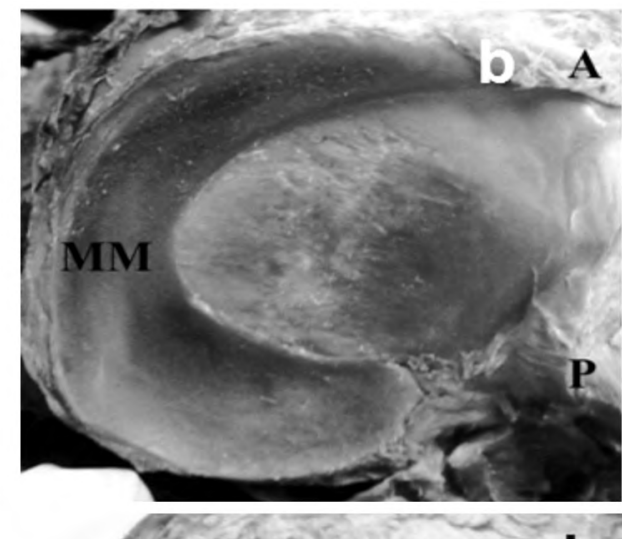

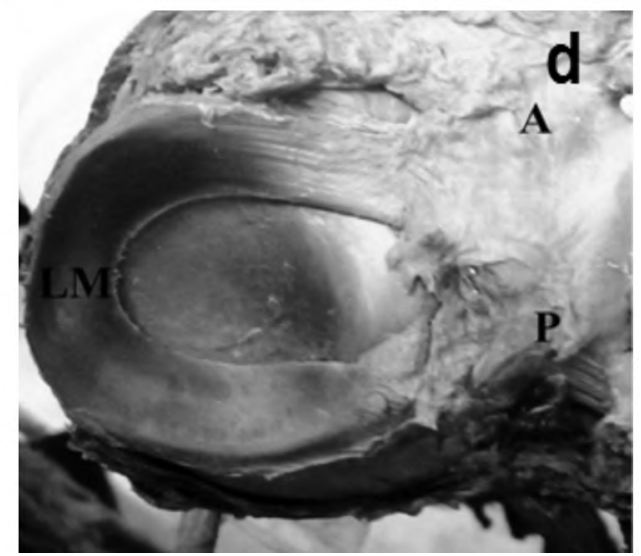

Fig. (1): (A): A photograph of top view of left tibial plateau of a human cadaver showing crescentic shaped medial meniscus. (B): A photograph of top view of right tibial plateau of a human cadaver showing sickle shaped medial meniscus. (C): A photograph of top view of left tibial plateau of a human cadaver showing C-shaped lateral meniscus. (D): A photograph of top view of left tibial plateau of a human cadaver showing sided U-shaped lateral meniscus. 

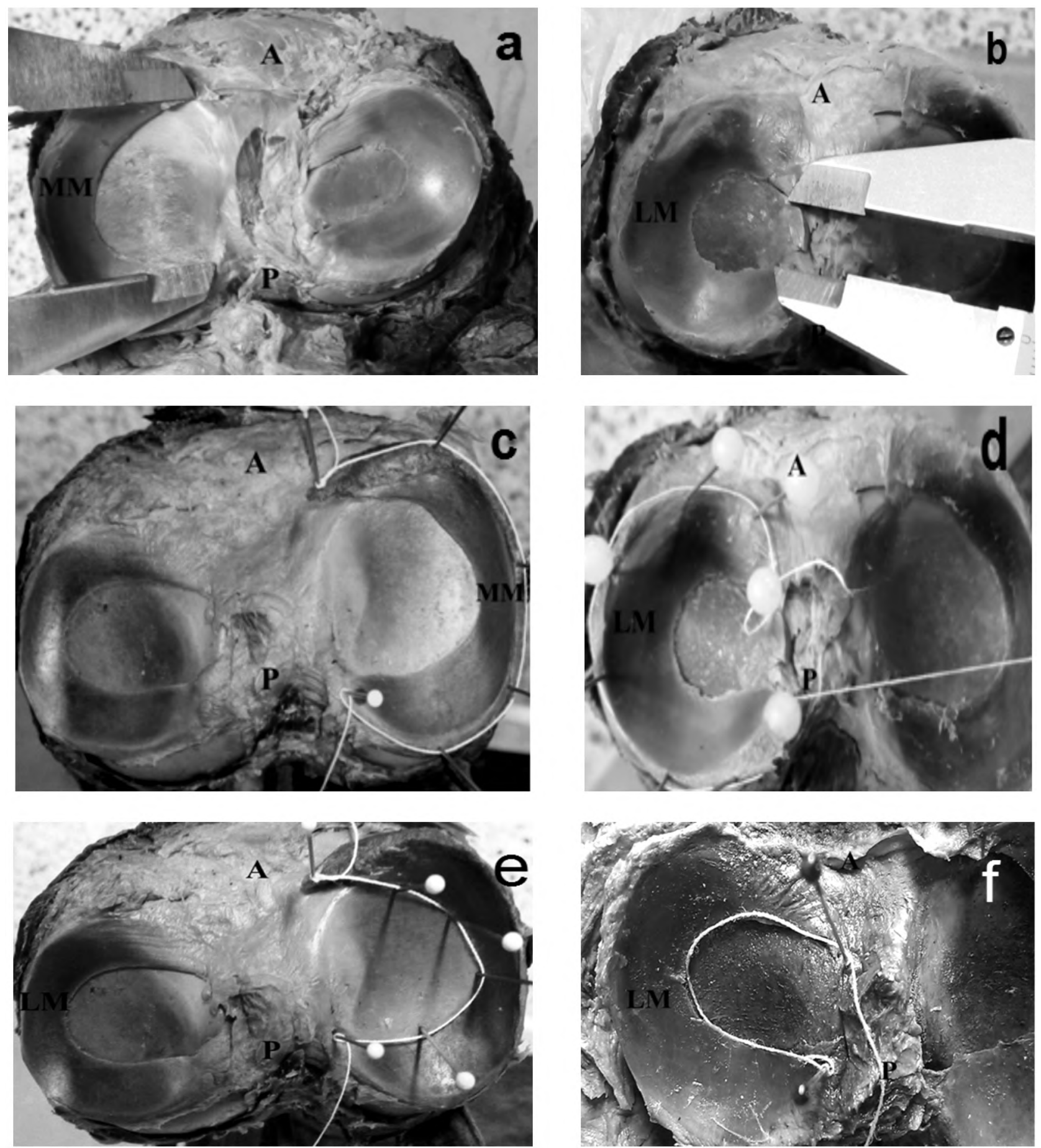

Fig. (2): (A): A photograph of top view of right tibial plateau of a human cadaver showing the measurement of the distance between the anterior and posterior horn of the medial meniscus. (B): A photograph of top view of left tibial plateau of a human cadaver showing the measurement of the distance between the anterior and posterior horn of the lateral meniscus. (C): A photograph of top view of left tibial plateau of a human cadaver showing the measurement of the outer circumference of the medial meniscus. (D): A photograph of top view of left tibial plateau of a human cadaver showing the measurement of the outer circumference of the lateral meniscus. (E): A photograph of top view of left tibial plateau of a human cadaver showing the measurement of the inner circumference of the medial meniscus. (F): A photograph of top view of left tibial plateau of a human cadaver showing the measurement of the inner circumference of the lateral meniscus. 

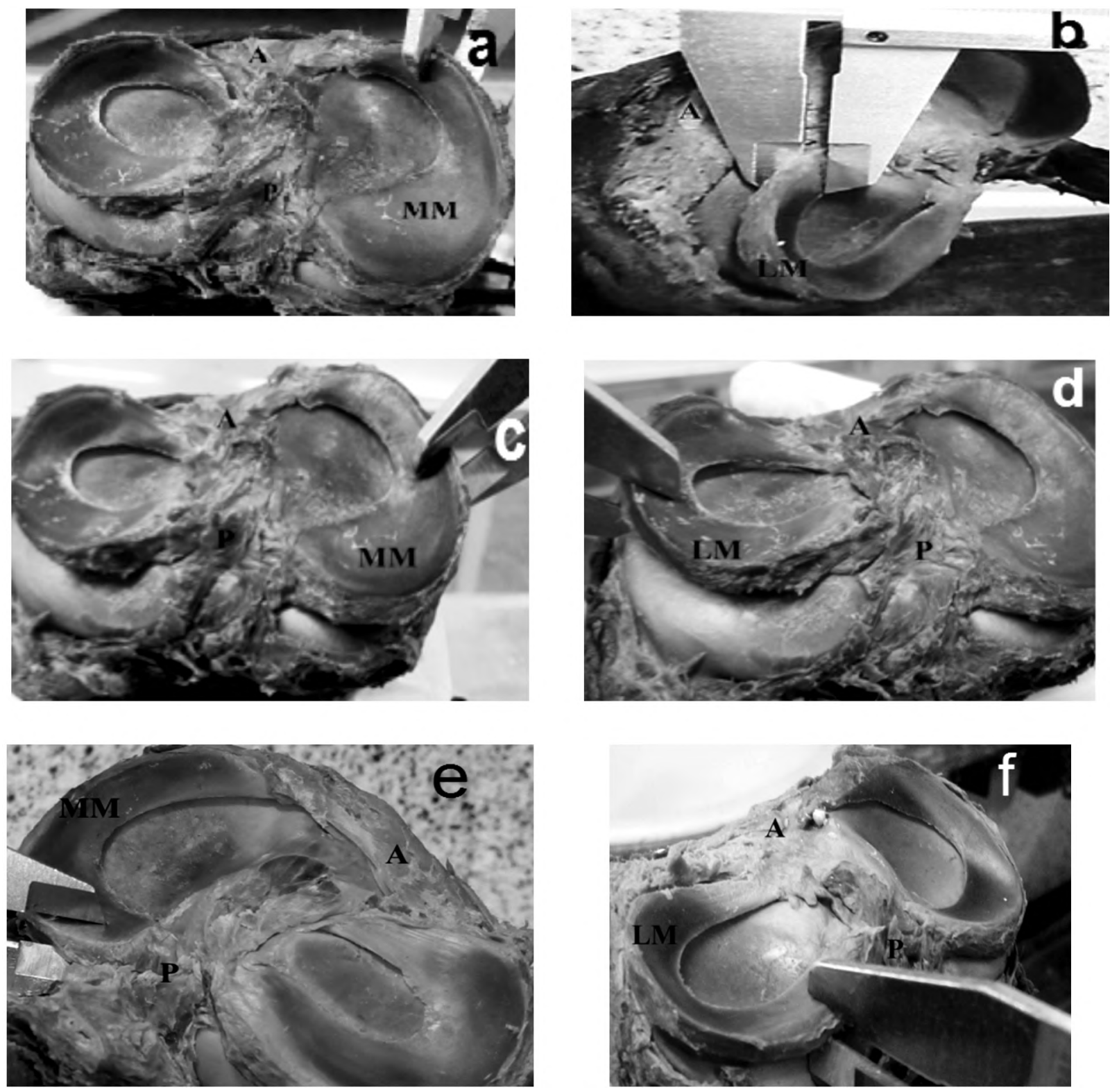

Fig. (3): (A): A photograph of top view of left tibial plateau of a human cadaver showing the measurement of thickness of anterior $1 / 3$ of the medial meniscus. (B): A photograph of top view of left tibial plateau of a human cadaver showing the measurement of thickness of anterior 1/3 of the lateral meniscus. (C): A photograph of top view of left tibial plateau of a human cadaver showing the measurement of thickness of middle $1 / 3$ of the medial meniscus. (D): A photograph of top view of left tibial plateau of a human cadaver showing the measurement of thickness of middle $1 / 3$ of the lateral meniscus. (E): A photograph of top view of right tibial plateau of a human cadaver showing the measurement of thickness of posterior $1 / 3$ of the medial meniscus. (F): A photograph of top view of left tibial plateau of a human cadaver showing the measurement of thickness of posterior $1 / 3$ of the lateral meniscus. 

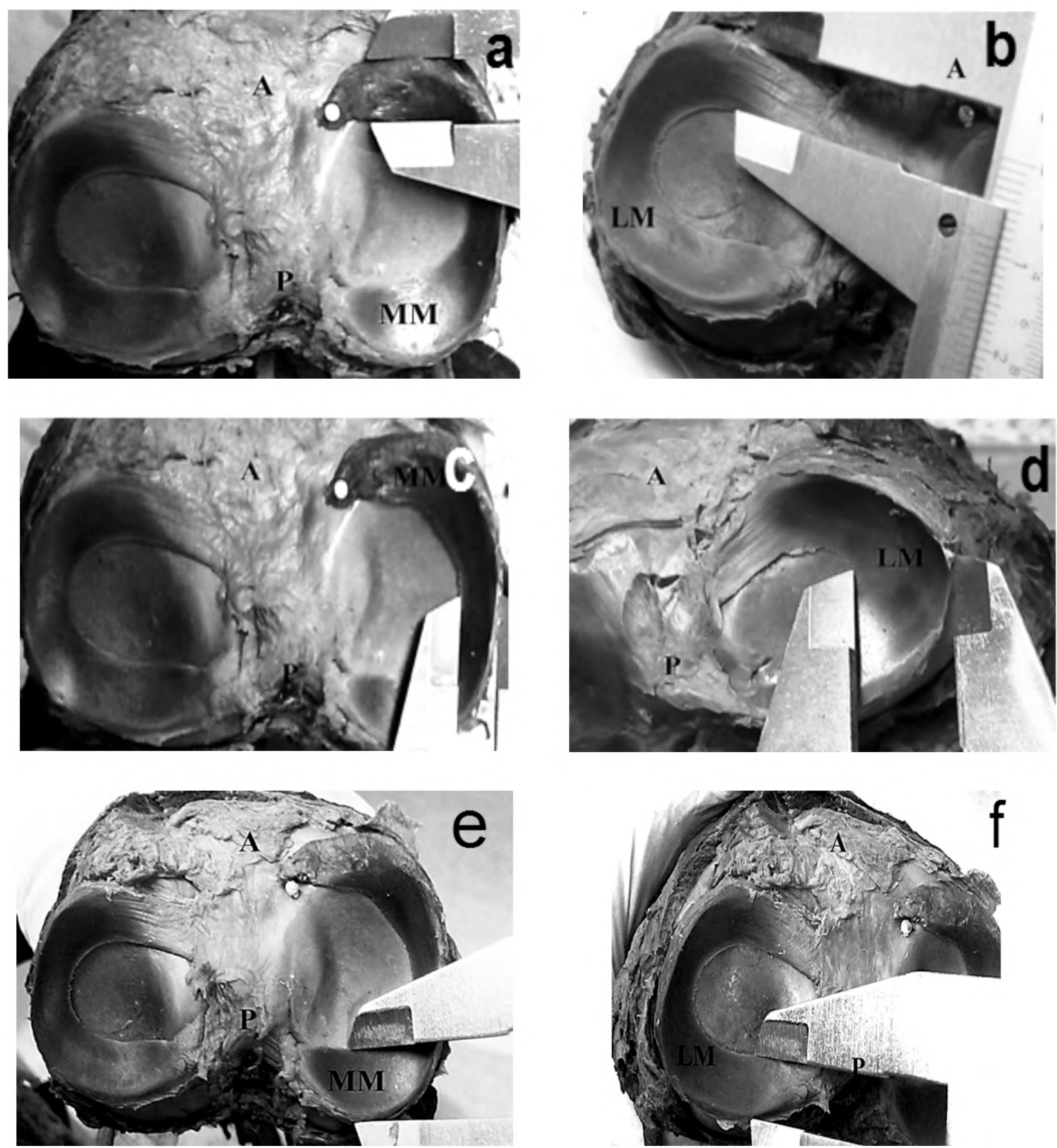

Fig. (4): (A): A photograph of top view of left tibial plateau of a human cadaver showing the measurement of the width of anterior $1 / 3$ of the medial meniscus. (B): A photograph of top view of left tibial plateau of a human cadaver showing the measurement of the width of anterior 1/3 of the lateral meniscus. (C): A photograph of top view of right tibial plateau of a human cadaver showing the measurement of the width of middle $1 / 3$ of the medial meniscus. (D): A photograph of top view of right tibial plateau of a human cadaver showing the measurement of the width of middle $1 / 3$ of the lateral meniscus. (E): A photograph of top view of left tibial plateau of a human cadaver showing the measurement of the width of posterior $1 / 3$ of the medial meniscus. (F): A photograph of top view of left tibial plateau of a human cadaver showing the measurement of the width of posterior $1 / 3$ of the lateral meniscus. 

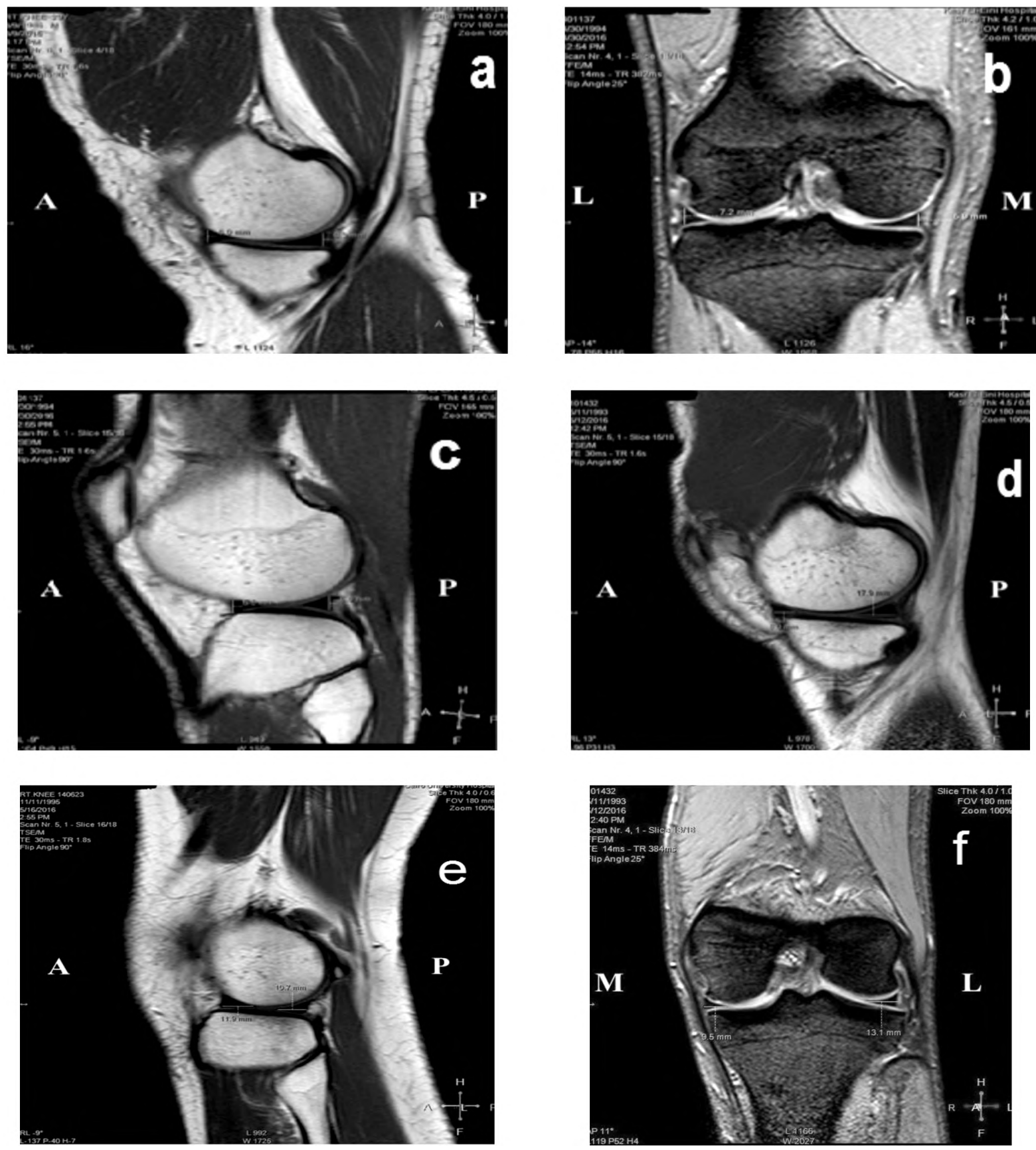

Fig. (5): (A): An MRI sagittal section PD of right knee joint showing measurement of the thickness of anterior and posterior horn of the medial meniscus. (B): An MRI sagittal section PD of right knee joint showing the measurement of the thickness of anterior and posterior horn of the lateral meniscus. (C): An MRI coronal section T2W Gradient FFE of right knee joint showing the measurement of the thickness of the mid-body of the medial and lateral menisci. (D): An MRI sagittal section PD of left knee joint showing the measurement of the width of anterior and posterior horn of the medial meniscus. (E): An MRI sagittal section PD of right knee joint showing the measurement of the width of anterior and posterior horn of the lateral meniscus (F): An MRI coronal section T2W Gradient FFE of left knee joint showing the measurement of the width of the mid-body of the medial and lateral menisci. 

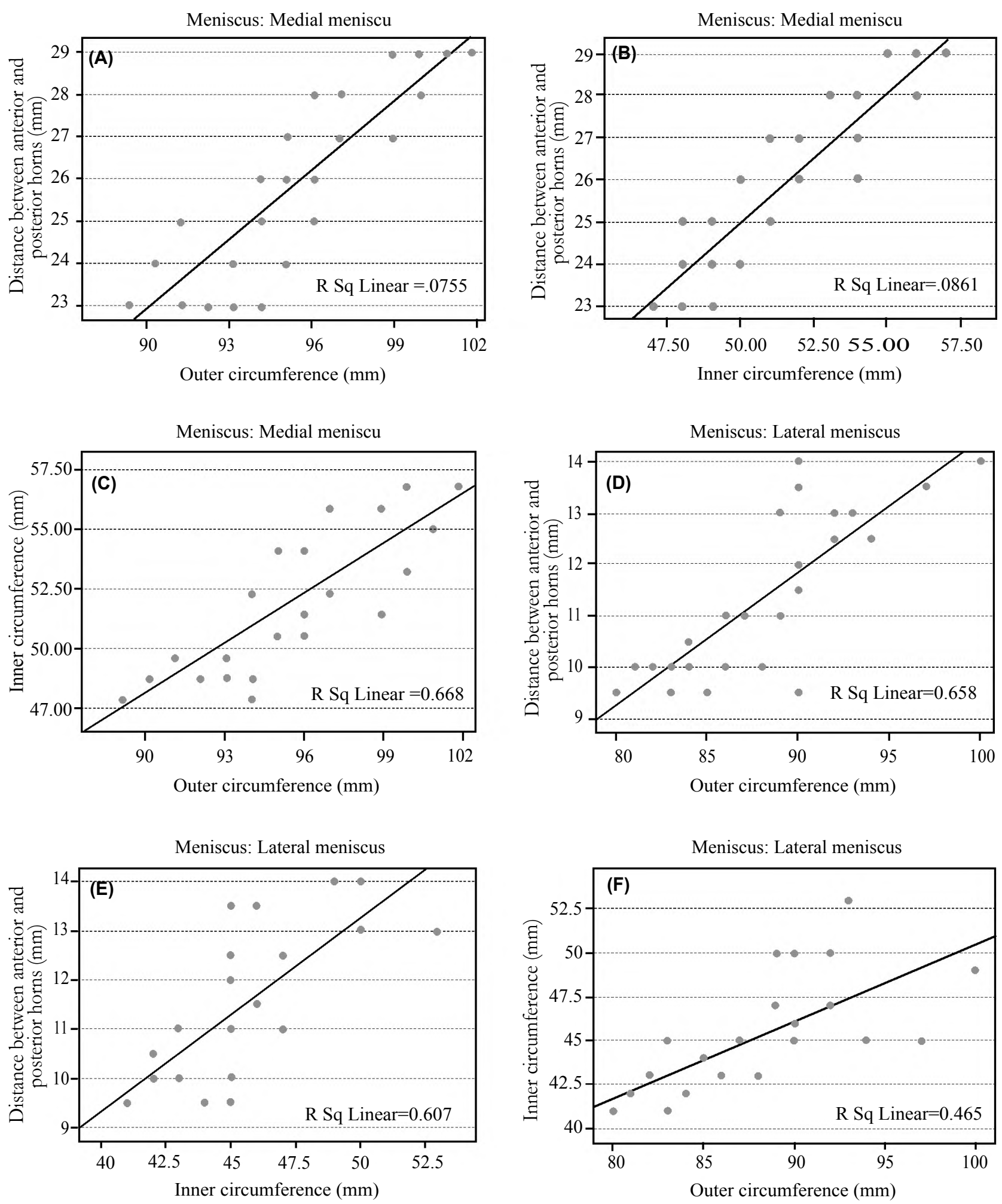

Fig. (6): (A): Scatterplot of a positive correlation between the outer circumference and the distance between the anterior and posterior horns of the medial meniscus. (B): Scatterplot of a positive correlation between the inner circumference and the distance between the anterior and posterior horns of the medial meniscus. (C): Scatterplot of a positive correlation between the outer and inner circumferences of the medial meniscus. (D): Scatterplot of a positive correlation between the outer circumference and the distance between the anterior and posterior horns of the lateral meniscus. (E): Scatterplot of a positive correlation between the inner circumference and the distance between the anterior and posterior horns of the lateral meniscus. (F): Scatterplot of a positive correlation between the outer and inner circumferences of the lateral meniscus. 

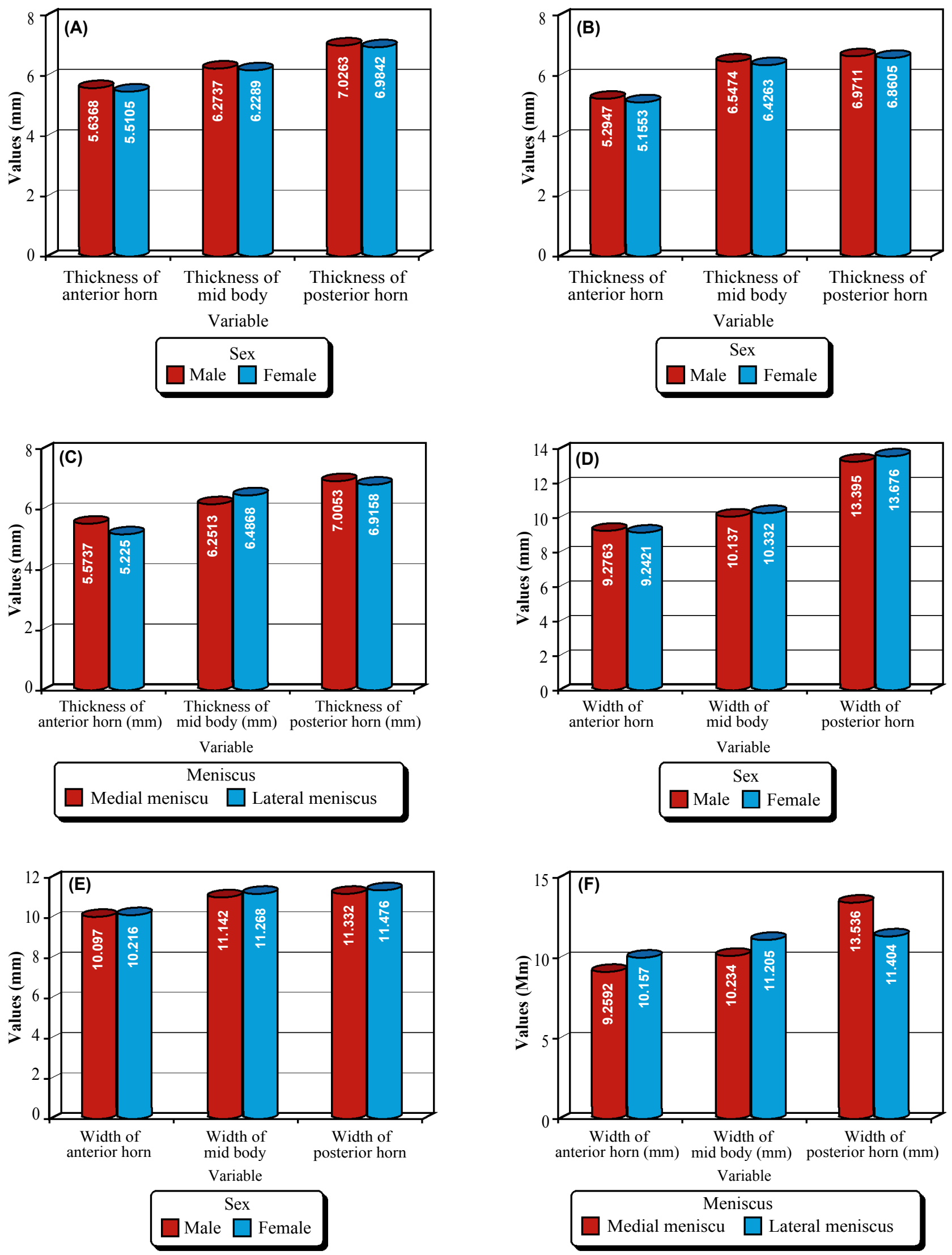

Fig. (7): (A): Bar chart of a comparison of the mean thickness of different parts of medial meniscus on basis of sex (B): Bar chart of a comparison of the mean thickness of different parts of lateral meniscus on basis of sex (C): Bar chart of a comparison of the mean thickness between the different parts of both menisci regardless sex. D: Bar chart of a comparison of the mean width between the different parts of medial meniscus on basis of sex (E): Bar chart of a comparison of the mean width of the different parts of lateral meniscus on basis of sex (F): Bar chart of a comparison of the mean width of different parts of both menisci regardless sex. 

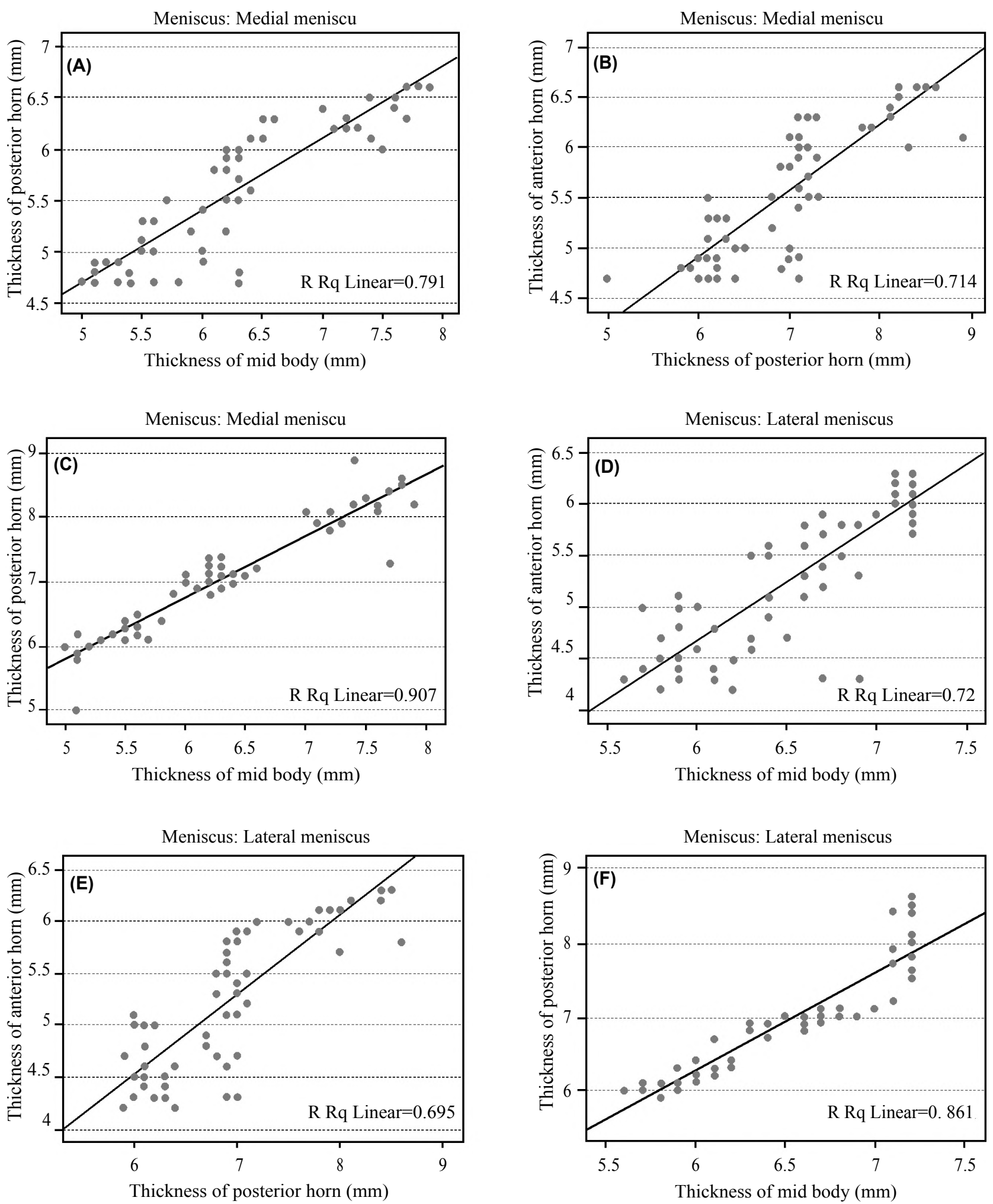

Fig. (8): (A): Scatterplot of a positive correlation between the thickness of the anterior horn and mid-body of the medial meniscus. (B): Scatterplot of a positive correlation between the thickness of the anterior and posterior horns of the medial meniscus. (C): Scatterplot of a positive correlation between the thickness of the posterior horn and mid-body of the medial meniscus. (D): Scatterplot of a positive correlation between the thickness of the anterior horn and mid-body of the lateral meniscus. (E): Scatterplot of a positive correlation between the thickness of the anterior and posterior horns of the lateral meniscus. (F): Scatterplot of a positive he correlation between the thickness of the posterior horn and mid-body of the lateral meniscus 

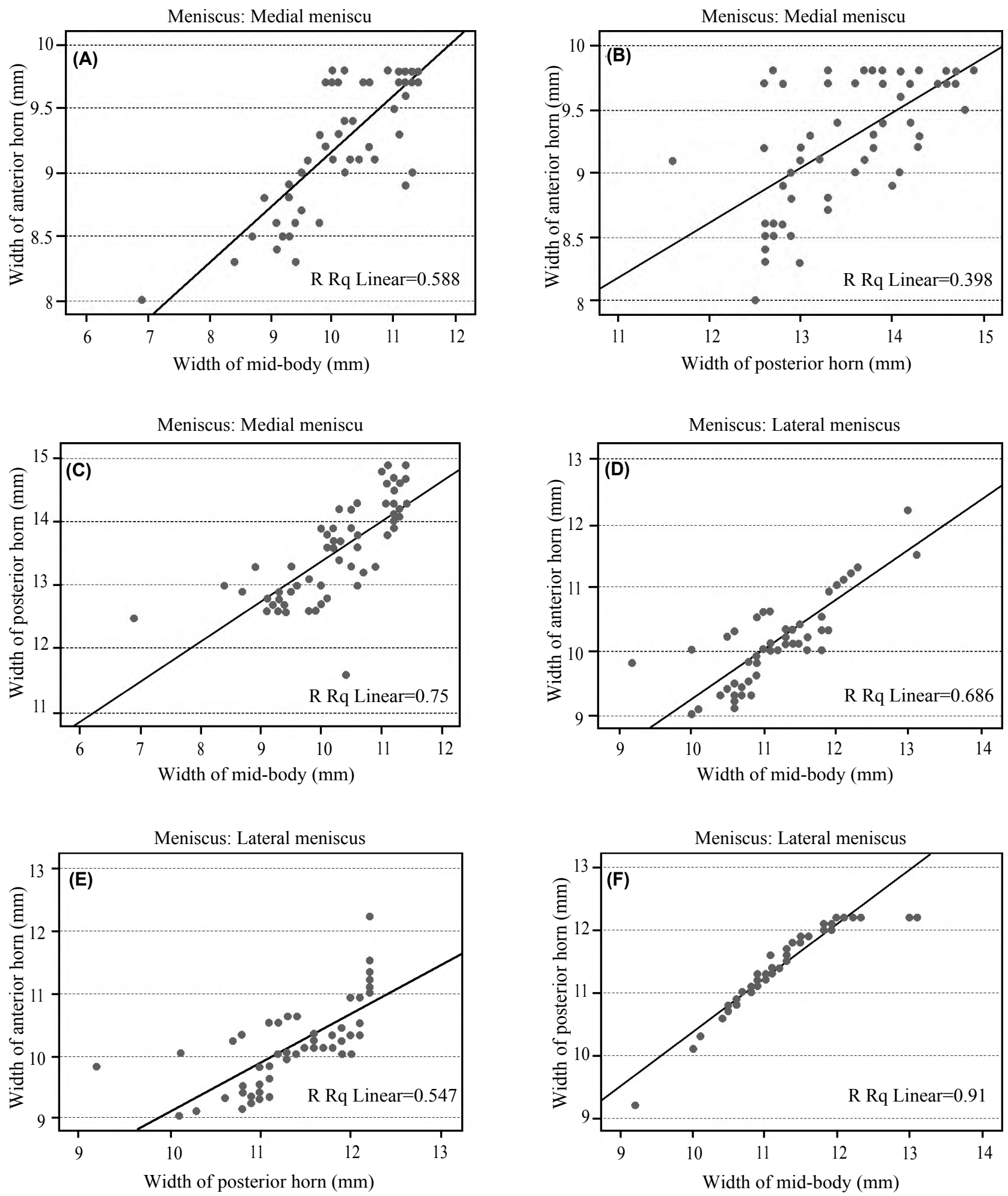

Fig. (9): (A): Scatterplot of a positive correlation between the width of the anterior horn and mid-body of the medial meniscus. (B): Scatterplot of a positive correlation between the width of the anterior and posterior horns the medial meniscus (C): Scatterplot of a positive correlation between the width of the posterior horn and mid-body of the medial meniscus. (D): Scatterplot of a positive correlation between the width of the anterior horn and mid-body of the lateral meniscus. (E): Scatterplot of a positive correlation between the width of the anterior and posterior horns the lateral meniscus. (F): Scatterplot of a positive correlation between the width of the posterior horn and mid-body of the lateral meniscus. 


\section{Discussion}

Meniscus injury is the most common injury encountered in practice, sports and everyday activities. Data related to the morphology and morphometric analysis of the menisci are scarce. Accordingly, the present study investigated diverse meniscal shapes and parameters in both adult human cadavers and in using MRI.

The cadaveric study included fifty menisci ( 25 medial and 25 lateral) and revealed variation in the shape of the menisci. The crescentic shape of medial meniscus was most frequent $(92 \%)$ and the sickle shape was least (8\%). This result is close to that of Itagi et al., [15] who studied 120 menisci from 60 adult cadaveric knee joints in Indian population and reported that $96.66 \%$ of medial menisci were crescentic shaped. Regarding the lateral meniscus, the most common shape was the C-shape (84\%). This comes in agreement also with Itagi et al., [15] who found that $88.33 \%$ of the lateral menisci were C-shaped.

The present cadaveric study revealed also that the mean distance between the anterior and posterior horn of the medial meniscus was $25.80 \pm 2.18$ $\mathrm{mm}$ which is identical to data by Braz and Silva [16] who worked on 40 menisci in Brazilian population and found it to be $25.8 \pm 3.33 \mathrm{~mm}$. On the other hand, Ashwini et al., [5] investigated 25 knees of formalin fixed adult human cadavers in Indian population and recorded a lower mean distance of $21.32 \pm 3.7 \mathrm{~mm}$. The difference might be due to racial variation.

Regarding the mean distance between the anterior and posterior horn of lateral menisci in the present cadaveric study, it was recorded as $11.36 \pm$ $1.58 \mathrm{~mm}$ which is so close to the result provided by Murlimanju et al., [6] who studied 23 adult knees of formalin fixed human cadavers in Indian population and reported it as $11.31 \pm 3.86 \mathrm{~mm}$, but is lower than that reported by Braz and Silva [16] as $12.55 \pm 1.98 \mathrm{~mm}$.

The present cadaveric study agreed with Braz \& Silva (2010) [16], Murlimanju et al., [6] and Ashwini et al., [5] who reported that the distance between the anterior and posterior horn was larger in medial menisci than in the lateral menisci due to the fact that the lateral meniscus has the form of an almost complete ring, whereas the medial is more like half a moon.

In the present cadaveric study, the mean value of the outer circumference of the medial meniscus was
$95.16 \pm 3.62 \mathrm{~mm}$. This result is higher than those recorded by Braz and Silva [16] who reported it to be $91.85 \pm 5.66 \mathrm{~mm}$, Ashwini et al., [5] who reported it as $90.12 \pm 8.0 \mathrm{~mm}$ and far more than Rao et al., [17] who studied 100 knees of the formalin fixed adult human cadavers in Indian population and found it to be $86.4 \pm 4.5 \mathrm{~mm}$. On the other hand, the present finding is lower than that of Murlimanju et al., [6] who recorded it as $99.06 \pm 11.21 \mathrm{~mm}$. These differences might be due to the technique used in the measurement as both the present study and the previous studies used linear measurement of a nonlinear structure.

The mean value of the outer circumference of the lateral meniscus in the present study was $88.20 \pm 4.95$ $\mathrm{mm}$ which is which is higher than that recorded by Rao et al., [17] $87.3 \pm 4.9 \mathrm{~mm}$, and much higher than the results of Ashwini et al., [5] who found it to be $83.28 \pm 7.4 \mathrm{~mm}$. On the other hand, the present result is lower than that of Murlimanju et al., [6] who reported it as $90.25 \pm 9.36 \mathrm{~mm}$. This discrepancy can be due to the technique used in the measurement as the cotton thread used in the present study and the previous studies is not the ideal technique for measuring a nonlinear structure.

Comparing the mean outer circumference of the medial and lateral menisci in the present work, the medial meniscus exhibited larger values than that of the lateral which was statistically significant. This finding is concordant with the results provided by Braz and Silva [16], Murlimanju et al., [6], Ashwini et al., [5] and Rao et al., [17]. This finding could be explained be the fact that the medial tibial condyle is larger than the lateral.

In the present cadaveric study, the mean inner circumference of the medial meniscus was $51.32 \pm$ $3.29 \mathrm{~mm}$ which was statistically significantly larger than that of lateral meniscus which was 45.28 $\pm 3.16 \mathrm{~mm}$. Similar findings were reported by Murlimanju et al., [6] and Ashwini et al., [5] .

In the present cadaveric study, the thickness of the midpoint of different parts of the meniscus (anterior, middle and posterior 1/3) was measured. To the extent of our knowledge the specific points of measurement of the menisci have not been exactly defined in the previous literature.

In the present cadaveric study, the mean thickness of these specified parts of the medial meniscus was $4.34 \pm 0.47 \mathrm{~mm}, 6.22 \pm 0.95 \mathrm{~mm}$ and $6.78 \pm 0.97 \mathrm{~mm}$ for anterior, middle and posterior thirds, respectively and was $4.16 \pm 0.45 \mathrm{~mm}, 5.74 \pm 0.71 \mathrm{~mm}$ and $6.62 \pm$ $0.85 \mathrm{~mm}$ for anterior, middle and posterior thirds of the lateral meniscus, respectively. These measurements 
are close to those measured by Takroni et al., [18] who studied 6 pairs of menisci of human knee male cadavers in Canadian population.

In the present cadaveric study, the thickness of the middle $1 / 3$ of the medial meniscus showed higher values than those of the lateral meniscus which was statistically significant. However, the values of thickness of the anterior and posterior $1 / 3$ of medial meniscus were also higher than the lateral, but these differences were statistically non-significant. This comes in agreement with Ashwini et al., [5] who suggested that the higher thickness of the middle third of the medial meniscus could explain the higher incidence of injuries in the medial meniscus relative to the lateral.

Comparing the thickness of different parts of the meniscus of the same side, the present cadaveric study showed that the posterior horn was the thickest part, followed by the mid-body, then the anterior horn with statistically significant difference in both lateral and medial menisci. Similar conclusions were provided by Ashwini et al., [5] . On the other hand, the present finding differs from data collected by Almeida et al., [4] who studied 44 menisci of 22 knees of adult Brazilian male cadavers and found that the anterior $1 / 3$ of the medial meniscus was the thickest part. Another contradictory result was provided by Rohila et al., [19] who studied 100 lateral menisci of adult human male cadavers in Indian population and found that the thickest part of the lateral meniscus was the middle third. This difference may be explained by the fact that the three measuring points used by those authors do not coincide with the exact points used in the present study.

In the present cadaveric study, the mean values of the width of anterior and middle thirds of medial meniscus were $8.92 \pm 0.67 \mathrm{~mm}$ and $10.24 \pm 1.59 \mathrm{~mm}$, respectively which are higher than those reported by Takroni et al., [18] as $8.5 \pm 0.62 \mathrm{~mm}$ for the anterior and $8.8 \pm 0.49 \mathrm{~mm}$ for the middle third. On the other hand, the mean value of the width of the posterior horn reported by the later $(14.8 \pm 0.7 \mathrm{~mm})$ was quite higher than that reported in the present study $(11.20$ $\pm 1.27 \mathrm{~mm})$.

The mean values of the width of the different parts of the lateral meniscus in the present work were $10.0 \pm 0.80 \mathrm{~mm}$ for the anterior $1 / 3,11.14 \pm 1.32 \mathrm{~mm}$ for the middle $1 / 3$ and $11.16 \pm 0.81 \mathrm{~mm}$ for the posterior $1 / 3$, which are lower than those reported by Takroni et al., [18] as $11.5 \pm 0.43 \mathrm{~mm}$ for the anterior $1 / 3,11.62$ $\pm 0.53 \mathrm{~mm}$ for the middle $1 / 3$ and $11.67 \pm 0.24 \mathrm{~mm}$ for the posterior third.
The present cadaveric study is in agreement with Rao et al., [17] who concluded that the measurements of width of anterior and middle 1/3 of lateral meniscus were much higher than those of medial meniscus which is statistically significant, while the posterior $1 / 3$ of medial meniscus was wider than the lateral but it was statistically nonsignificant.

The present cadaveric study comes in accordance with Almeida et al., [4], Murlimanju et al., [6], Ashwini et al., [5] and Takroni et al., [18] who reported that the posterior horn of lateral and medial menisci are the widest part of the meniscus and the anterior horn is the narrowest. Murlimanju et al., [6] suggested that the narrow meniscus is less prone to rupture than the wide one, the greater the width of the meniscus, the more the exposure to friction and compression. Rico and Ayala [20] pointed out that the anterior third of medial menisci are rarely injured.

In the present cadaveric study, there was a statistically significant positive correlation between the length of the outer circumference, length of inner circumference and distance between anterior and posterior horn of the meniscus, both in medial and lateral menisci. Such correlation has not been addressed in any previous literature.

Meniscus transplantation has gained much attention and shown clinical applicability in recent years; appropriate sizing of the meniscal allograft is crucial in restoring the meniscal function. Undersized grafts result in poor congruity with the femoral condyle and may experience an excessive lo ad, whereas oversized grafts are predisposed to extrusion, resulting in inadequate transmission of a compressive load across the knee [21]. The present radiological study estimated the mean thickness and width of different parts of both medial and lateral menisci using MRI; the most recent, accurate and less invasive methodology basically used in visualizing soft tissues [22]

The present study is the first to compare radiological measurements of the medial menisci with the lateral in healthy adult knees in Egyptian population.

The present radiological study showed that the mean of thickness of different parts of the medial meniscus was $5.57 \pm 0.65 \mathrm{~mm}$ for anterior horn, 6.25 $\pm 0.68 \mathrm{~mm}$ for mid-body and $7.01 \pm 0.82 \mathrm{~mm}$ for posterior horn which are quite similar to those of Dhananjaya et al., [23] who examined eighty menisci from forty knee joints of Indian population using 
MRI and reported it as $6.3 \pm 1.1 \mathrm{~mm}, 5.2 \pm 1.3 \mathrm{~mm}$ and $6.9 \pm 1.1 \mathrm{~mm}$, respectively.

The present radiological study showed that the mean of thickness of different parts of the medial meniscus was $5.57 \pm 0.65 \mathrm{~mm}$ for anterior horn, 6.25 $\pm 0.68 \mathrm{~mm}$ for mid-body and $7.01 \pm 0.82 \mathrm{~mm}$ for posterior horn which are quite similar to those of Dhananjaya et al., [23] who examined eighty menisci from forty knee joints of Indian population using MRI and reported it as $6.3 \pm 1.1 \mathrm{~mm}, 5.2 \pm 1.3 \mathrm{~mm}$ and $6.9 \pm 1.1 \mathrm{~mm}$, respectively.

In the present study, the mean thickness of different parts of lateral meniscus was $5.23 \pm$ $0.68 \mathrm{~mm}$ for anterior horn, $6.49 \pm 0.52 \mathrm{~mm}$ for midbody and $6.92 \pm 0.72 \mathrm{~mm}$ for posterior horn which are close to those of Dhananjaya et al., [23] who reported it as $4.8 \pm 0.7 \mathrm{~mm}, 6.4 \pm 1.1 \mathrm{~mm}$ and $7.0 \pm 0.9$ $\mathrm{mm}$, respectively.

Comparing the mean thickness of different corresponding parts of medial and lateral menisci, the present study found that the anterior horn of the medial meniscus was thicker than the lateral and it was statistically significant, while the midbody of the lateral meniscus was thicker than the medial and it was statistically significant. The values of posterior horn of medial meniscus were higher than the lateral but it was statistically nonsignificant.

In contrary to the present study, Erbagci et al., [13] studied normal menisci in 174 healthy Turkish subjects by using MRI and reported that there was no significant difference between the thickness of the posterior horn and the mid-body between the two menisci. However, as reported in the present study the thickness of the anterior horn of the medial meniscus was statistically significantly higher than that of the lateral meniscus. On other hand, an MRI study conducted by Bloecker et al. [24] on 122 knees in Columbian population reported that the thickness of anterior horn and the midbody of the lateral meniscus were higher than those of the medial meniscus but the opposite for the posterior horn. These contradictory results may be due to different software or plane used for measurement.

In the present MRI study, both medial and lateral menisci were found to be thickest at their posterior horn followed by the mid-body then the anterior horn. This comes in total agreement with Erbagci et al., [13] and Bloecker et al., [24].

Dhananjaya et al., [23] reported the same observation regarding the lateral meniscus but contra- dictory findings were claimed in the medial meniscus where the posterior horn was the thickest part followed by the anterior horn then the mid-body. This difference could be attributed to the small sample size studied by those authors.

In the present MRI study, the mean width of the medial meniscus was $9.26 \pm 0.50 \mathrm{~mm}$ for the anterior horn, $10.23 \pm 0.89 \mathrm{~mm}$ for the mid-body and $13.54 \pm 0.74 \mathrm{~mm}$ for the posterior horn which is much higher than findings recorded by Erbagci et al., [13] who reported them as $7.78 \pm 1.86 \mathrm{~mm}$, $7.37 \pm 2.65 \mathrm{~mm}$ and $11.71 \pm 2.63 \mathrm{~mm}$, respectively.

In the present MRI study, the mean values of the width of anterior and posterior horn of the lateral menisci were $10.16 \pm 0.64 \mathrm{~mm}$ and $11.40 \pm$ $0.61 \mathrm{~mm}$, respectively which are lower than those recorded by Dhananjaya et al., [23] as $11.8 \pm 1.4 \mathrm{~mm}$ $12.0 \pm 0.9 \mathrm{~mm}$, respectively. While the mean value of the width of the mid-body reported by the later $(8.6 \pm 1.2 \mathrm{~mm})$ is much lower than that recorded in the present study $(11.21 \pm 0.67 \mathrm{~mm})$.

The present MRI study comes in accordance with Erbagci et al., [13] and Dhananjaya et al., [23] that the anterior horn and mid-body of the lateral meniscus were wider than the medial and it was statistically significant. Contrarily, the posterior horn of the medial meniscus was wider than that of the lateral and it was statistically significant.

Comparing the width of the different parts of the meniscus of the same side, the present MRI study found that the posterior horn is the widest part of the meniscus followed by the mid-body then the anterior horn in both lateral and medial menisci and this was statistically significant. On the other hand, Erbagci et al., [13] and Dhananjaya et al., [23] found that the posterior horn was the widest followed by the anterior horn then the midbody. This discrepancy may be due to different planes used for measurement.

In the present MRI study, the mean values of thickness and width of different parts of both menisci in males were slightly higher than those of females; however this sex difference was statistically non-significant.

In contrast, Erbagci et al., [13] reported that the thickness and width of the posterior horn of the medial and lateral menisci in males were higher than females and these differences were statistically significant. Also, Bloecker et al., [24] reported that meniscal width was larger in males than in females. This contradiction may be due to the relatively large sample size included in these studies com- 
pared to the present study; 174 knees by the former and 122 kness by the latter authors.

The present study reported a statistically significant positive correlation between the anterior horn, mid-body and posterior horn of the meniscus of the same side regarding the thickness and the width. Such parameter has not been previously addressed.

\section{References}

1- STANDRING S., HEALY J.C., JOHNSON D., et al.: Knee joint, lower limb. In: Gray's Anatomy; the anatomical basis of clinical practice, 41 th edition. Churchill Livingstone, Edinburgh, pp. 1902-1917, 2016.

2- SINNATAMBY C.S.: Last's Anatomy, Regional and Applied, 11 th Edition, Edinburgh, Churchill Livingstone, Elsevier Health Sciences, 173-184, 2011.

3- FOX A.J., BEDI A. and RODEO S.A.: The basic science of human knee menisci: Structure, composition, and function. Sports Health, 4 (4): 340-351, 2012.

4- ALMEIDA K.S., MORAES S.R., TASHIRO T., et al.: Morphometric study of menisc of the knee joint. International Journal of Morphology, 22 (3): 181-184, 2004.

5- ASHWINI C., NANJAIAH, C. M. and SARASWATHI G.S.: Morphometrical study of menisci of human knee joint. International Journal of Current Research and Review, 5 (8): 118-125, 2013.

6- MURLIMANJU B.V., NAIR N., Kumar B., et al.: Clinically oriented morphometric study of medial and lateral menisci of the knee joint in adult cadavers. La Clinica terapeutica, 163 (2): 105-108, 2012.

7- HARPER K.W., HELMS C.A., LAMBERT III H.S. and HIGGINS L.D.: Radial meniscal tears: Significance, incidence, and MR appearance. American Journal of Roentgenology, 185 (6): 1429-1434, 2005.

8- KELLY B.T. and GREEN D.W.: Discoid lateral meniscus in children. Current Opinion in Pediatrics, 14 (1): 54-61, 2002.

9- TACHIBANA Y., YAMAZAKI Y. and NINOMIYA S. Discoid medial meniscus. Arthroscopy: The Journal of Arthroscopic \& Related Surgery, 19 (7): e59-e65, 2003.

10- NAKAJIMA T., NABESHIMA Y., FUJII H., et al.: Symptomatic anomalous insertion of the medial meniscus. Arthroscopy: The Journal of Arthroscopic \& Related Surgery, 21 (5): 629-633, 2005.

11- HERON D., BONNARD C., MORAINE C., et al.: Agenesis of cruciate ligaments and menisci causing severe knee dysplasia in TAR syndrome. Journal of Medical Genetics, 38 (8): e27-e27, 2001.
12- UTKAN A., ÖZKAN G., KOSE C. C., et al.: Congenital absence of the medial meniscus associated with lipoma arborescens. The Knee, 17 (3): 258-260, 2010.

13- ERBAGCI H., GUMUSBURUN E., BAYRAM M., et al.: The normal menisci: in vivo MRI measurements. Surgical and Radiologic Anatomy, 26 (1): 28-32, 2004.

14- LEFEVRE N., NAOURI J.F., HERMAN S., et al.: A current review of the meniscus imaging: Proposition of a useful tool for its radiologic analysis. Radiology Research and Practice: 1-25, 2016.

15- ITAGI V., SHIROL V.S., and JAYASUDHA K.: Morphology of menisci of knee joint in adult cadavers of north karnataka. International Journal of Current Research and Review, 7 (5): 43-47, 2015.

16- BRAZ P.R.P. and SILVA W.G.: Meniscus morphometric study in humans. Journal of Morphological Science, 27 (2): 62-66, 2010.

17- RAO N., GUPTA A.D. and RAJU A.V.: Morphometric analysis of the menisci of the knee joint in population of east godavari region of andhra pradesh. Journal of evolution of medical and dental sciences, 1 (3): 8972-8979. 2014.

18- TAKRONI T., LAOUAR L., ADESIDA .A., et al.: Anatomical study: Comparing the human, sheep and pig knee meniscus. Journal of Experimental Orthopaedics, 3 (1): 1-13, 2016.

19- ROHILA J., RATHEE S.K. and BANSAL S.: Morphometric analysis of lateral menisci in North Indian population: A cadaveric study. International Journal of Research in Medical Sciences, 4 (7): 2745-2749, 2017.

20- RICO C., EDUARDO G. and ABREGO AYALA C.E.: Localización de las rupturas meniscales en nuestro medio. Revista mexicana ortopedia. Traumatol., 11 (1): 10-13, 1997.

21- YOON J.R., KIM T.S., WANG J.H., et al.: Importance of independent measurement of width and length of lateral meniscus during preoperative sizing for meniscal allograft transplantation. The American Journal of Sports Medicine, 39 (7): 1541-1547, 2011.

22- FOX A.J., WAIVENHAUS F., BURGE A.J., et al.: The human meniscus: A review of anatomy, function, injury, and advances in treatment. Clinical Anatomy, 28 (2): 269287,2015 .

23- DHANANJAYA K.V.N., MURLIMANJU B., POORNIMA V., et al.: In vivo morphometry of menisci of the knee in South Indians: A preliminary study. Biomedical Journal, 37 (1): 14-17, 2014.

24- BLOECKER K., WIRTH W., HUDELAMAIER M., et al.: Morphometric differences between the medial and lateral meniscus in healthy men-a three-dimensional analysis using magnetic resonance imaging. Cells Tissues Organs, 195 (4): 353-364, 2012. 


\section{دراسة تشريحية مورفوميترية للغضاريف الهلالية

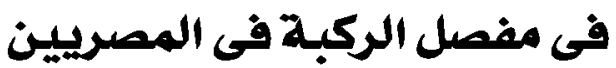

إصعابة الغضرف الهلالى شائعة فى الهياة اليومية وكذلك فى الرياضات وخاصة لاعبى كرة القدم.

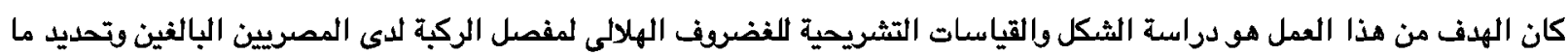

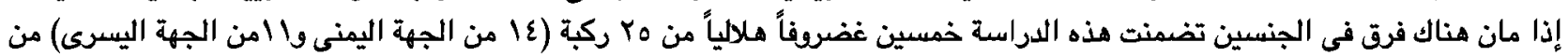

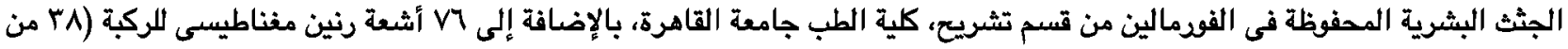

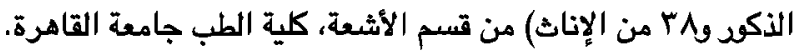

أثتبت الدراسة الحالية على الجثت أن الشكل الهلالى هو الاكثر شيوعاً للغضروف الهلالى الأنسى أما شكل حرف C هو الاكثر شيوعاً بالنسبة اللغضرف الهلائى الوحشى.

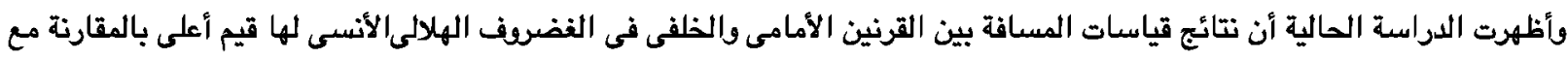

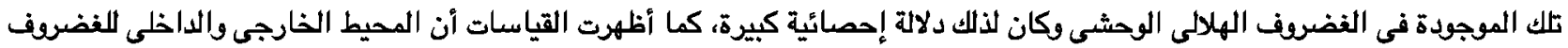

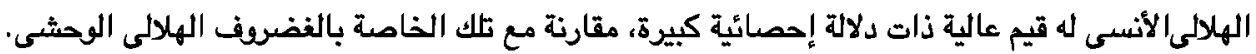
وكان هناك إرتباط إحصائى إيجابى قوى بين قياسات المحيط الخارجى والمحيط الداخلى والمسافة بين القرنين الأمامى والخلفى من الهن

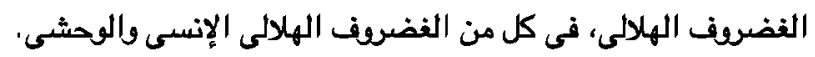

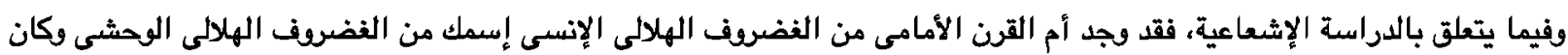

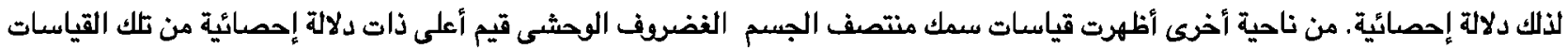

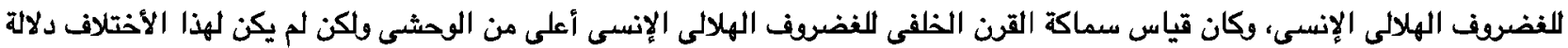

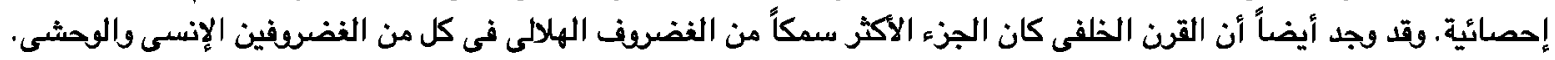

أما بالنسبة لقياسات العرض للأجزاء المختلفة للغضروفين فقد كان قياسات عرض القرن الأمامى ومنتصف الجسم من الغضروف الهلالى

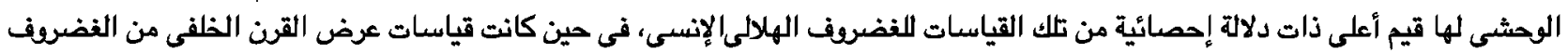

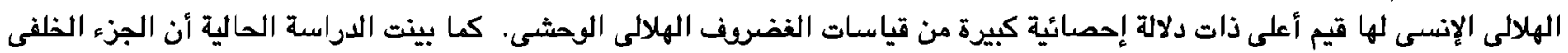
من القرن عو أعرض جزء فى الغضروف في كل من الغضروف الهلالى الإنسى والوحشى.

وقد أظهرت أيضاً الدراسة الإشعاعية الحالية أن القياسات المختلفة فى الذكود لها قيم أعلى من الإناث لكن لم يكن لهذا الأختلاف دلالة إحصائية. ونستنتج من ذلك أن قياس سمك وعرض الأجزاء المختلة للفضروف الهلالى المفصلى أساسى قبل الزرع لأن القياس الدقيق هو أهم عامل لنجاح عملية زراعة الغضروف. 